\title{
CRISE FISCAL DOS ESTADOS E O CASO DO RIO DE JANEIRO
}

\section{STATE FISCAL CRISES, AND THE CASE OF RIO DE JANEIRO}

\author{
Guilherme Mercês ${ }^{1}$, Nayara Freire ${ }^{1}$ \\ ${ }^{1}$ Federação das Indústrias do Estado do Rio de Janeiro (FIRJAN), Rio de Janeiro, RJ, Brasil
}

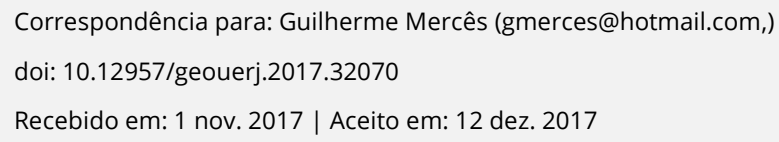

\section{RESUMO}

Este artigo analisa a situação fiscal dos estados, com foco no Rio de Janeiro. Além da dívida, examinamos as variáveis-chave na dinâmica das contas públicas estaduais: gastos de pessoal, restos a pagar e investimentos. A primeira conclusão é que a dívida é problema para poucos estados. A segunda conclusão é que a crise fiscal tem caráter estrutural, em que pese a queda das receitas decorrente da recessão econômica. Está relacionado ao elevado comprometimento do orçamento com despesas de pessoal, especialmente por conta do desequilíbrio previdenciário. Dessa forma, momentos de queda na receita se traduzem em elevados déficits. Além disso, a rigidez orçamentária tem resultado em graves problemas de liquidez, retratados pelo uso excessivo de restos a pagar sem a devida cobertura de caixa. Em vista desse diagnóstico, concluímos também que a adesão ao regime de recuperação fiscal proposto pelo governo federal parece inevitável aos estados do Rio de Janeiro, do Rio Grande do Sul e de Minas Gerais. As contrapartidas exigidas pelo acordo, contudo, não são suficientes para evitar que em poucos anos seja necessária mais uma renegociação das dívidas subnacionais.

Palavras-chave: Dívida, Previdência, Restos a pagar, Investimentos.

\section{ABSTRACT}

This article analyzes public accounts of Brazilian states, focusing on Rio de Janeiro. We examined the public debt and the key indicators for public account dynamics: staff costs, accounts payable, and investments. The first conclusion is that few states have a debt problem. The second conclusion is that the fiscal crisis is structural, notwithstanding the fall in revenues due to the economic recession. It is related to the high budget staff cost fixed share, especially due to social security imbalance. Thus, moments of fall in revenues result in high deficits. In addition to that, budget rigidity has resulted in great liquidity problems, which are expressed by the excessive use of accounts payable without equivalent cash flow hedge. Consequently, we also concluded that commitment to the fiscal recovery program proposed by the Federal Government seems inevitable to the states of Rio de Janeiro, Rio Grande do Sul and Minas Gerais. The agreement requirements, however, are not enough to prevent new renegotiation of state debts in a few years.

Keywords: Debt, social security, accounts payable, investments.

\section{INTRODUÇÃO}

O desequilíbrio fiscal e a necessidade de ajuste das contas públicas, nos três níveis de governo, têm dominado o debate econômico. Em âmbito federal, a escalada da dívida pública motivou a determinação constitucional inédita de limitar o crescimento dos gastos públicos, bem como o encaminhamento de reformas fundamentais à sustentabilidade fiscal de longo prazo, como a da previdência. 
O quadro fiscal talvez seja ainda mais grave nos estados, na medida em que sequer há recursos para pagar funcionários e fornecedores em alguns casos, prejudicando a prestação de serviços públicos essenciais. De fato, muitos entes federativos estão à beira da insolvência, tendo como agravante o fato de que já estão descumprindo os limites impostos pela Lei de Responsabilidade Fiscal - LRF. Isso significa que, além dos riscos fiscais, há riscos sociais e politico-institucionais.

No estado do Rio de Janeiro, a situação econômica e fiscal é das mais graves. Em 2016, a JUCERJA ${ }^{1}$ registrou o maior número de empresas extintas em 17 anos (14.439 mil). Os dados CAGED ${ }^{2}$ também ilustram o cenário de deterioração da atividade. Apenas em 2015 e 2016, foram extintos 420 mil postos de trabalho, número superior ao registrado na década de 90, quando foram extintas 389 mil vagas no estado. Consequência disso, houve forte queda da arrecadação de tributos, mais intensa inclusive que a da atividade econômica. Enquanto a produção industrial acumulou queda de 4,0\% em 2016, a arrecadação de ICMS do setor apresentou retração de 15,7\%, segundo dados do IBGE e da Secretaria de Fazenda do estado. Nesse ambiente, o Rio de Janeiro decretou estado de calamidade financeira e iniciou negociações com o governo federal em vistas à um novo plano de recuperação fiscal.

Este artigo analisa a situação fiscal das 27 unidades da federação brasileira, com foco no Rio de Janeiro. Além da dívida, examinamos o comportamento das variáveis-chave na dinâmica das contas públicas estaduais: gastos de pessoal (ativo e inativo), restos a pagar e investimentos. Como veremos, no Rio de Janeiro, o encolhimento das receitas causou enorme desequilíbrio em um orçamento altamente comprometido com despesas obrigatórias, notadamente as de caráter previdenciário. A verdade é que há pouca margem de manobra para adequar as despesas à capacidade de arrecadação, o que deixa as contas públicas fluminenses extremamente expostas à conjuntura econômica.

O quadro se repete por quase todo o Brasil. Pelo lado da receita, a recessão resultou em forte redução da arrecadação. Pelo lado do gasto, o desafio é a gestão das despesas de pessoal ativo e inativo, uma

\footnotetext{
${ }^{1}$ Junta Comercial do Estado do Rio de Janeiro.

${ }^{2}$ Cadastro Geral de Empregados e Desempregados do Ministério do Trabalho e Emprego.
} 
vez que a rigidez orçamentária decorrente da sua expansão exagerada pode comprometer os recursos programados para outros fins, em especial os investimentos. E como os estados têm pouco acesso ao mercado de crédito, usam cada vez mais a postergação de despesas via restos a pagar como fonte de financiamento, o que tem gerado graves problemas de liquidez.

O trabalho tem três outras seções, além desta introdução. A segunda apresenta a restrição orçamentária dos estados, bem como a metodologia de cálculo dos indicadores fiscais analisados. A terceira seção faz uma análise comparada dos resultados das vinte sete unidades da federação, com foco no estado do Rio de Janeiro. A última seção sintetiza as conclusões.

\section{Metodologia}

Os governos estaduais, como todos os demais agentes da economia, não podem expandir de maneira arbitrária seus gastos, sendo necessário que existam recursos, próprios ou de terceiros, para custeálos. Rezende (2001) caracteriza o setor público como sendo um agente econômico que se defronta com uma restrição orçamentária cujo equilíbrio exige uma igualdade entre o fluxo de dispêndios e a entradas de recursos. Caso contrário, haverá excedente (superávit) ou falta (déficit) de recursos. No primeiro caso, o governo acumulará poupança e poderá utilizá-la para fazer investimentos. No segundo, o governo necessitará buscar financiamento, ou seja, aumentará a sua dívida.

A análise das contas públicas subnacionais, contudo, não deve se restringir a evolução da dívida e do déficit, como faz tradicionalmente a análise macroeconômica da política fiscal. Isso porque a partir do acordo com o Governo Federal, no final da década de 1990, os estados e municípios tiveram sua dívida refinanciada e foram proibidos de emitir dívida mobiliária, ficando, portanto, impedidos de se endividar frente a um déficit orçamentário. Assim, as medidas de déficit "abaixo da linha", construídas na década de 1980 e divulgadas mensalmente pelo Banco Central, deixaram de ser o melhor termômetro fiscal para estados e municípios. 
O resultado fiscal medido pela diferença entre os fluxos de receitas e despesas, conhecido como "acima da linha", permite melhor acompanhamento da situação fiscal dos entes federativos. Outra variável importante a ser considerada são os restos a pagar, pois se tornaram a principal fonte de financiamento não só para os estados, mas também para os municípios. De fato, explicam movimentos de desequilíbrio fiscal que muitas vezes não são revelados pelos indicadores de estoque, como a dívida consolidada. Representam o que podemos chamar de déficit "entre linhas".

Na restrição orçamentária dos governos subnacionais o fluxo de dispêndios deve ser igual ao de entrada de recursos:

Receitas $=$ Despesa $(1)$

No caso dos estados, as fontes de financiamento disponíveis são: a) a receita corrente (RC), composta pelas receitas tributárias próprias do estado e pelas transferências da União; b) o endividamento, representado pela variação da dívida $(\Delta \mathrm{DIV})$; e c) o artifício da postergação do pagamento de despesas, contabilizado por meio dos Restos a Pagar (RAP).

Substituindo o lado esquerdo da equação (1) temos:

$\mathrm{RC}+\Delta \mathrm{DIV}+\Delta \mathrm{RAP}=\operatorname{Despesas}(2)$

Pelo lado das despesas, os estados possuem os seguintes comprometimentos: despesas correntes primárias (DC), onde se encontram os gastos com pessoal e custeio da máquina; encargos da dívida pública (Amortização e Juros); e Investimentos (I). Substituindo estes termos em (2):

$\mathrm{RC}+\Delta \mathrm{DIV}+\Delta \mathrm{RAP}=\mathrm{DC}+($ Amort $+\mathrm{J})+\mathrm{I}(3)$

Esta é a restrição orçamentária dos estados brasileiros. A equação mostra que a capacidade de investimento de um estado depende da relação entre seu potencial de arrecadação (RC) e seus gastos 
rígidos $(\mathrm{DC}+$ Amort $+\mathrm{J})$, e do comprometimento do orçamento corrente com despesas de exercícios anteriores (RAP), bem como da sua capacidade de endividamento. Essa equação servirá como base para as análises apresentadas nas seções seguintes. Especificamente, avaliaremos os cinco indicadores definidos abaixo:

i) Dívida: o indicador consiste na relação entre a Dívida Consolidada Líquida (DCL) e a Receita Corrente Líquida (RCL), considerando-se que a LRF determina que os estados não podem adquirir dívida superior a $200 \%$ da RCL.

ii) Despesas de Pessoal: para avaliar o efetivo comprometimento das receitas com essas despesas, foram descontadas da Despesa Bruta de Pessoal (despesa com pessoal ativo, inativos e pensionistas e outras despesas com pessoal decorrentes de contratos de terceirização) as receitas previdenciárias (contribuição dos segurados e receitas previdenciárias intra-orçamentárias).

iii) Restos a pagar: 0 indicador considera a disponibilidade de caixa bruta, descontados os restos a pagar processados, ponderada pela Receita Corrente Líquida (RCL). Nesta nota foram utilizados apenas dados referentes ao Executivo de cada estado. Em último ano de mandato, a LRF proíbe que essa relação seja negativa, ou seja, que o volume de restos a pagar seja superior aos recursos em caixa.

iv) Investimentos: mede a parcela dos investimentos nos orçamentos estaduais, isto é, a relação entre os investimentos e a Receita Corrente Líquida (RCL). Para garantir o crescimento econômico sustentado da economia brasileira e, sobretudo, o fornecimento dos serviços necessários à população, o investimento público é variável chave (FERREIRA, 1996; AFONSO e JUNQUEIRA, 2009).

A base de dados utilizada para o cálculo dos indicadores são as estatísticas oficiais declaradas pelos próprios estados e consolidadas pela Secretaria do Tesouro Nacional - STN. A Lei de 
Responsabilidade Fiscal (LRF), em seu artigo 51, determina que até 30 de abril de cada ano os entes devem encaminhar suas contas referentes ao exercício anterior para a STN, que tem 60 dias para disponibilizá-las ao público. Da mesma forma, também é exigido por lei a divulgação dos relatórios fiscais, o Relatório Resumido de Execução Orçamentária (RREO) e o Relatório de Gestão Fiscal (RGF). Ambos disponibilizados pela STN e pelas Secretarias da Fazenda de cada estado.

\section{Crise fiscal dos estados e o caso do Rio de Janeiro A dívida dos estados e a relação histórica com Governo Federal}

A literatura sobre o histórico de endividamento dos entes subnacionais remete o agravamento da situação fiscal dos estados ao final da década de 60. A reforma tributária de 1966 resultou na concentração dos tributos na esfera federal e, consequentemente, em menor autonomia tributária aos governos subnacionais. Somou-se isso o maior acesso ao mercado financeiro ${ }^{3}$, o que permitiu que 0 endividamento fosse a opção de financiamento frente a menor autonomia tributária, em detrimento de um ajuste das despesas. Os bancos estatais tiveram papel-chave nesse processo, atuando não só na rolagem da dívida como também na alavancagem de recursos junto aos governos estaduais. Como consequência, na década de 80, o endividamento dos entes subnacionais tomou proporções insustentáveis.

Em vista desse quadro, a Constituição de 1988 promoveu uma ampla descentralização das receitas em favor das esferas subnacionais. Além disso, em 1989 ocorreu uma tentativa da União de conter a escalada da dívida dos entes subnacionais. A Lei Federal nº 7.976 de 1989 autorizou o financiamento pela União, com prazo de 20 anos, das dívidas de responsabilidade dos estados, dos municípios e de entidades de suas administrações indiretas. Contudo, a abrangência da Lei não foi suficiente para resolver o problema de endividamento, uma vez que não contemplou o refinanciamento da dívida mobiliária. No caso do Rio de Janeiro, dados da Secretaria de Fazenda do Estado mostram que a dívida mobiliária representava mais da metade da dívida total à época.

\footnotetext{
${ }^{3}$ Resolução nํㅜ 63, de 21 de agosto de 1967
} 
Em 1993, Lei Federal nº 8.727 significou um novo financiamento da dívida junto à União, criando um mecanismo de vinculação dos pagamentos da dívida com a receita, e um limite para os encargos. A partir de 1994, na esteira do Plano Real, o governo federal passou a concentrar seus esforços no sentido de impor maior disciplina fiscal aos entes federados. Nesse sentido, diversas foram as mudanças institucionais que influenciaram o comportamento fiscal dos estados, dentre as quais é importante destacar a Lei 9.496/1997 e a Lei Complementar 101/2000, conhecida como Lei de Responsabilidade Fiscal (LRF).

A Lei 9.496/1997 autorizou a União a assumir a dívida pública mobiliária dos estados e municípios, assim como outras obrigações decorrentes de operações de crédito. Além disso, os bancos estaduais foram privatizados e os estados ficaram proibidos de emitir títulos de dívida, ou seja, foi o fim da emissão de dívida mobiliária por parte dos governos subnacionais. Os contratos de refinanciamento deveriam ser pagos em um prazo de 30 anos, e seriam reajustados por juros compostos de acordo com o IGP-DI acrescido de taxa pré-fixada de $6 \%$ a 9,0\% ao ano. O programa teve ampla adesão dos governos estaduais; as exceções foram Amapá e Tocantins.

No que tange à forma de pagamento, ficou estabelecido o limite de gastos com juros e amortizações de $12,0 \%$ e de $12,5 \%$, nos anos de 1999 e 2000, respectivamente; e de 13,0\% da Receita Líquida Real (RLR), a partir do ano de 2001. Importante destacar que o valor de cada prestação que excedesse o limite para encargos, deveria ser acumulado para pagamento nos meses em que o serviço da dívida refinanciada fosse inferior ao referido limite. Ou seja, se os gastos com juros e amortizações ultrapassassem o limite legal, o resíduo seria acrescido ao estoque da dívida.

A assinatura do contrato de refinanciamento pelas Unidades da Federação junto à União estava condicionada ao estabelecimento de um Programa de Apoio à Reestruturação e ao Ajuste Fiscal dos Estados (PAF). O Programa de Ajuste Fiscal surgiu para determinar metas fiscais trienais para os entes, entre as quais o resultado primário e o limite para as despesas com funcionalismo público e para a dívida. A assinatura de um programa de ajuste e a cobrança rigorosa pelo cumprimento das metas 
fiscais passou a ser a principal característica desta nova etapa de refinanciamento das dívidas subnacionais.

Nos últimos anos, a grande recessão da economia brasileira e a consequente queda expressiva da arrecadação pautaram questionamentos ao acordo firmado na Lei 9.496 de 1997. O resultado foi a Lei 148/2014, que definiu o aumento do prazo de pagamento da dívida por mais 20 anos, reduzindo assim o valor das parcelas pagas e trazendo alívio aos caixas. Além disso, houve mudança do indexador, que passou a ser a menor das variações acumuladas entre o IPCA mais 4\% a.a. e a taxa Selic, substituindo assim os encargos contratuais originais (IGP-DI acrescido de taxa pré-fixada de $6 \%$ a 9,0\% ao ano). Ademais, em junho de 2016, ainda com caixa insuficiente para cumprir suas obrigações, os estados fecharam um acordo com o governo federal e ficaram sem pagar a dívida por seis meses, além de terem recebido descontos nas parcelas até julho de 2018, quando os pagamentos retornarão ao valor total.

Os dados de endividamento agregado dos estados brasileiros mostram que as medidas tomadas ao longo desses anos conseguiram de fato reduzir o nível da dívida estadual - gráfico 1. Entre 2000 e 2016, a relação dívida receita recuou 53,0 p.p. O quadro é de fato favorável para a grande maioria dos estados. Das 27 unidades da federação, 22 encerraram 2016 com dívida inferior a 100\% RCL, sendo que 14 não chegaram a $50 \%$.

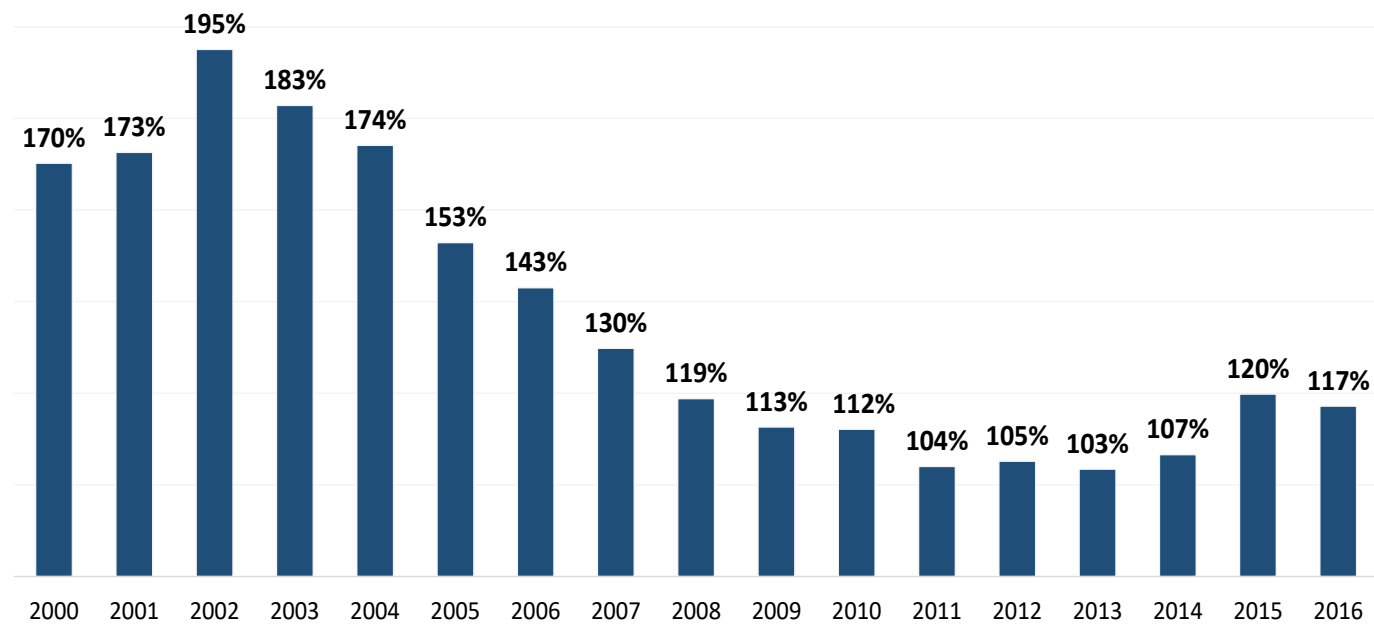

Gráfico 1: Dívida Consolidada Líquida \% RCL Estado do RJ

Fonte: Secretaria do Tesouro Nacional. Elaboração Própria. 
$\mathrm{Na}$ verdade, a dívida se manteve como problema apenas para quatro estados: Rio de Janeiro (232\% da Receita Corrente Líquida - RCL), Rio Grande do Sul (213\%), Minas Gerais (203\%) e São Paulo $(175 \%)$ - os três primeiros inclusive já ultrapassaram o limite de $200 \%$ da RCL estabelecido pela LRF. Essa concentração é explicada em grande parte pela forma de pagamento definida na renegociação de 1997, apresentada acima. Para os estados cujos estoques da dívida eram elevados à época, os limites impostos para pagamento de juros e amortização resultaram em elevado acumulo de resíduos.

O Rio de Janeiro é o estado com a dívida mais alta do país: 234\% da RCL. O gráfico 2 mostra a trajetória de endividamento do estado neste milênio. Assim como no agregado dos Estados, a dívida fluminense teve trajetória cadente na década de 2000, quando recuou de 234,8\% em 2002 para 145,8\% da RCL em 2011. A partir de então, cresceu de forma acelerada, até que em 2016 praticamente retornou ao nível de 2002. Em outras palavras, nos últimos quatro anos a dívida fluminense reverteu praticamente toda a redução observada nos nove anos anteriores.

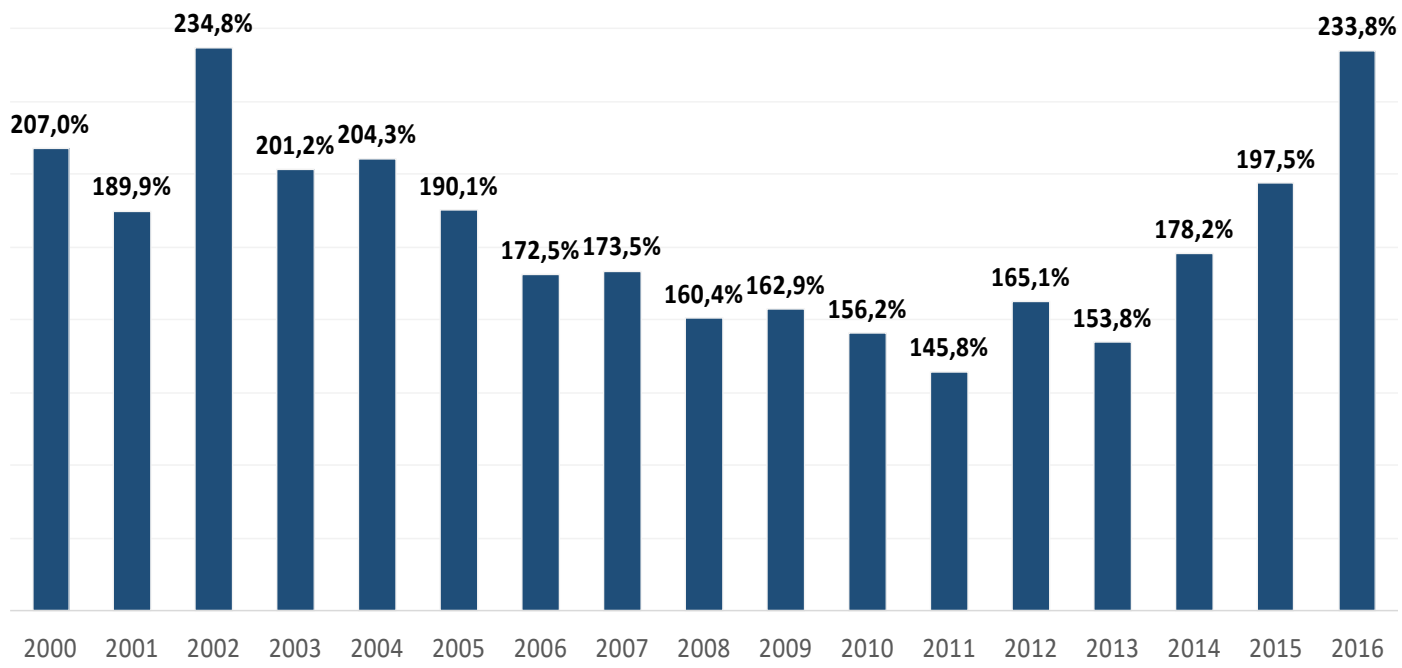

Gráfico 2. Dívida Consolidada Líquida \% RCL Estado do RJ. Fonte: Secretaria do Tesouro Nacional. Elaboração Própria.

\section{As contas estaduais nos últimos dezesseis anos e o caso do Rio de Janeiro}

A trajetória explosiva da Dívida a partir de 2013 resultou do acúmulo de sucessivos déficits, como mostra o gráfico 3. Há cinco anos o estado apresenta um orçamento deficitário, os recursos financeiros 
são insuficientes para cobrir as despesas primárias. Contribuiu para este cenário a forte queda da atividade que resultou na deterioração da arrecadação, a indústria fluminense acumulou queda de 13,1\% entre 2012 e 2016. No mesmo período, a Receita Primária registrou queda de 37,2\%, com isso, retornou, em termos reais, ao mesmo nível de 2004. De fato, a queda da Receita foi um fator importante, mas não o único para explicar o desequilíbrio fiscal do estado nos últimos anos. Mesmo com a queda da receita, o ajuste das despesas não foi suficiente para manter o equilíbrio das contas. As despesas foram reduzidas em 29,9\% no período, retornando ao nível registrado em 2009.

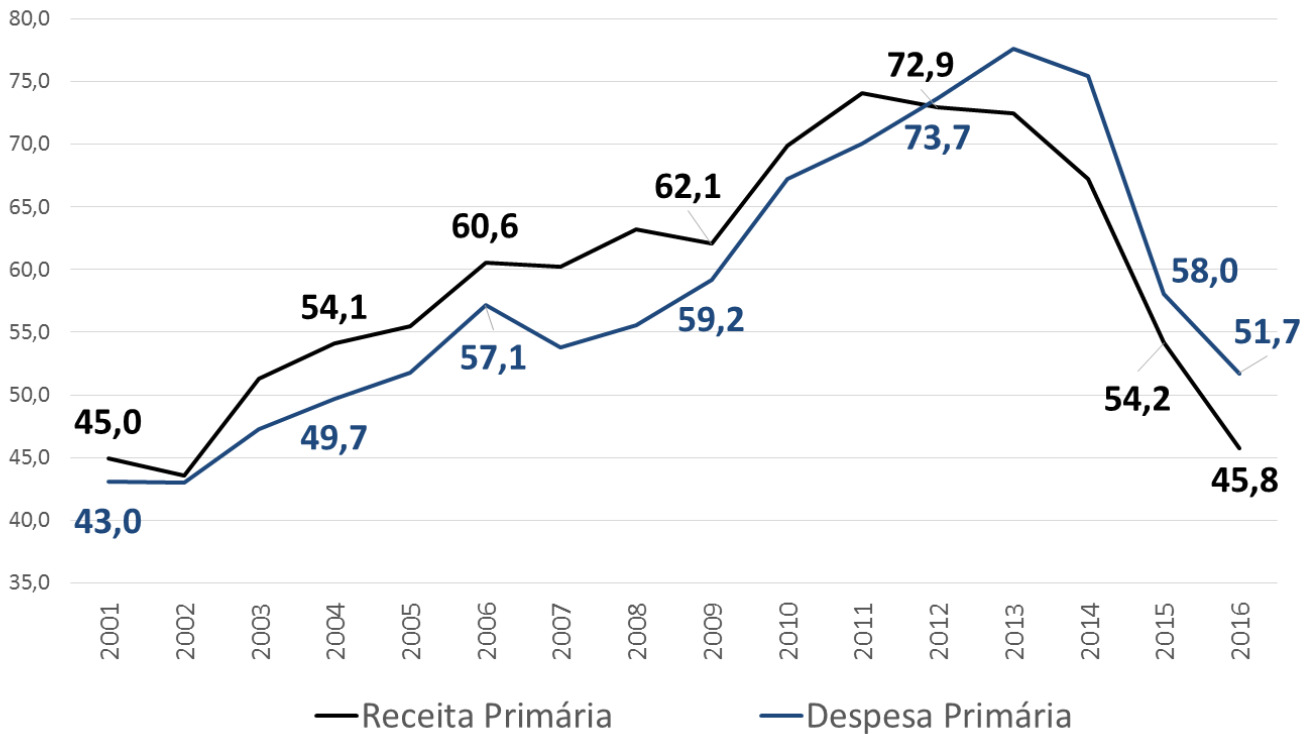

Gráfico 3. Receita e Despesa Primária - Valores reais (IPCA) Estado do RJ.

Fonte: Secretaria da Fazenda do estado do Rio de Janeiro. Elaboração Própria.

Em que pese a conjuntura econômica recessiva e seu consequente efeito negativo sobre a arrecadação tributária, o problema das contas públicas estaduais é estrutural e está relacionado ao elevado comprometimento dos orçamentos com gastos obrigatório, notadamente despesas de pessoal. Dessa forma, momentos de queda na receita, como o atual, se traduzem em elevados déficits. A verdade é que há pouca margem de manobra para adequar as despesas à capacidade de arrecadação, deixando as contas públicas extremamente expostas à conjuntura econômica.

Esta é uma realidade para a grande maioria dos estados brasileiros. 0 gráfico 4 apresenta as despesas com pessoal dos estados brasileiros, como proporção da RCL. Em média, esse percentual foi de 57,2\% em 2016 - acima portanto do limite prudencial definido pela LRF. No topo da lista estão Minas 
Gerais, onde as despesas de pessoal comprometeram 78\% da RCL, Rio Grande do Sul, com 76\% e Rio de Janeiro, com $72 \%$.

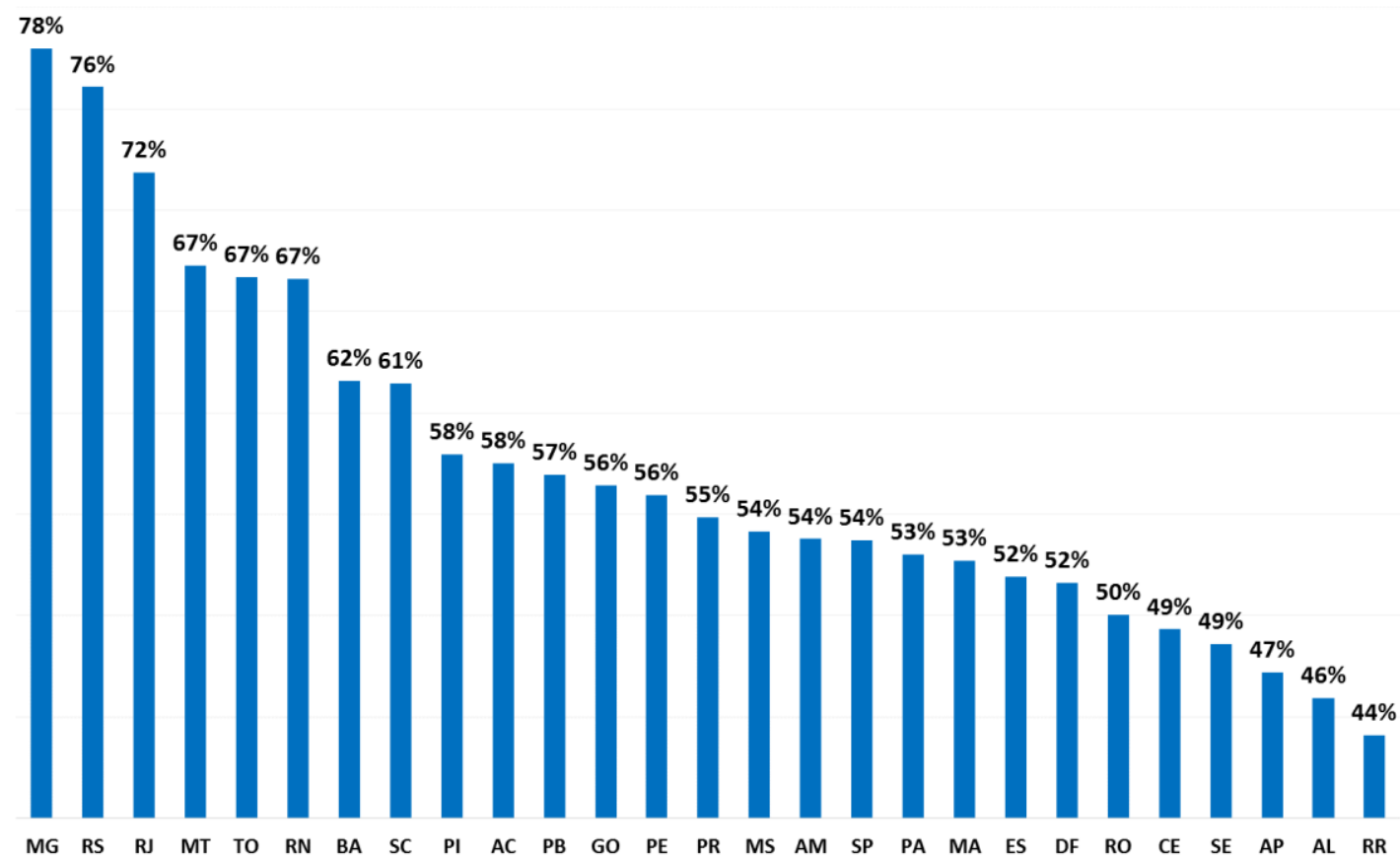

Gráfico 4. Despesa Líquida com Pessoal \% RCL Unidades da Federação. Fonte: Secretaria do Tesouro Nacional. Elaboração Própria.

O conceito aqui utilizado foi o de Despesa Líquida de Pessoal, que considera as despesas brutas com pessoal descontadas apenas as receitas previdenciárias (contribuição do servidor e receitas intraorçamentárias). Dessa forma, é possível apurar o verdadeiro comprometimento do orçamento com despesas de pessoal. Esse conceito difere do apurado por alguns estados, pois não desconta das despesas de pessoal receitas de qualquer outro tipo que não sejam previdenciárias.

O caso do Rio de Janeiro é emblemático nesse sentido. Durante muitos anos, o estado descontou as receitas de Royalties das despesas previdenciárias - no ano de 2015, o governo também utilizou de $\mathrm{R} \$ 6,4$ bilhões em depósitos judiciais para o mesmo fim. Essas receitas, que não são previdenciárias, mascararam o alto comprometimento do orçamento público com despesas de pessoal. Isso explica o grande salto do gasto das despesas de pessoal fluminense em 2016, evidenciado no gráfico 5. Com a brusca redução das receitas de royalties e sem a ajuda de depósitos judiciais, as duas metodologias 
praticamente se igualaram, deixando o estado do Rio de Janeiro muito acima dos 60\% da RCL definido pela LRF como teto para as despesas com funcionalismo.

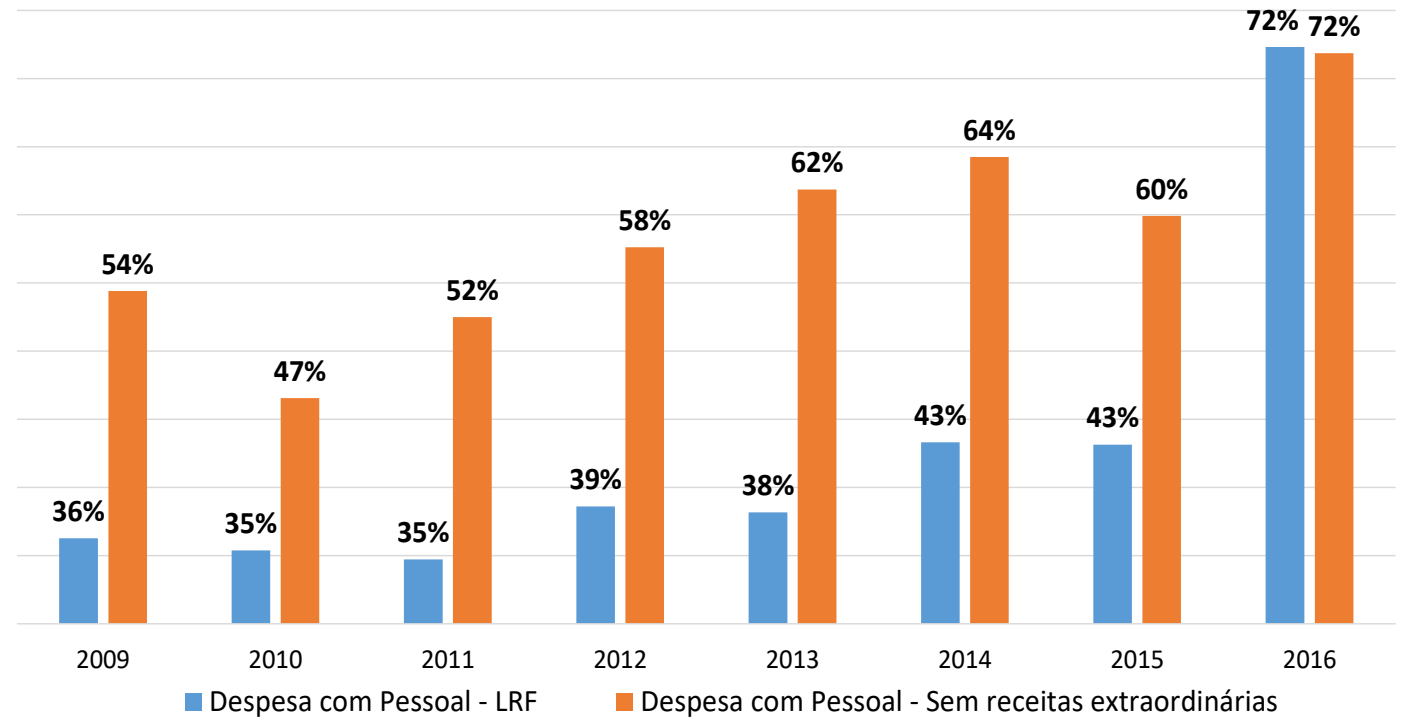

Gráfico 5. Despesa Líquida com Pessoal \% RCL Estado do Rio de Janeiro.

O financiamento da Previdência Social é de fato um dos grandes desafios às contas públicas, pelo simples fato do volume de contribuições não fazer frente ao de benefícios. Dados da FIRJAN (2017) mostram que em 2016 os estados tiveram que aportar $\mathrm{R} \$ 79,5$ bilhões em recursos do tesouro para cobrir o déficit financeiro em seus regimes de previdência ${ }^{4} ; 24$ estados tiveram que aportar, em média, $11,0 \%$ da RCL para cobrir as despesas com inativos e pensionistas. Conforme o gráfico 6, em apenas três estados a previdência não fechou o ano no vermelho: Rondônia, Roraima e Amapá. No Rio Grande do Sul 40,4\% da RCL foi direcionada para cobertura do déficit da previdência. Esse déficit supera $20 \%$ da RCL em Minas Gerais (27,8\%) e Rio de Janeiro (21,0\%). No Rio de Janeiro, a trajetória do déficit financeiro da previdência é ascendente - era de 13,7\% em 2008; só foi pontualmente interrompida em 2015, quando o governo utilizou de depósitos judiciais para reduzir o rombo previdenciário.

\footnotetext{
${ }^{4}$ De acordo com Caetano (2016), o alto desequilíbrio de curto prazo das previdências estaduais tem como consequência um déficit atuarial dos estados da ordem de $\mathrm{R} \$ 2,4$ tri (44\% do PIB).
} 


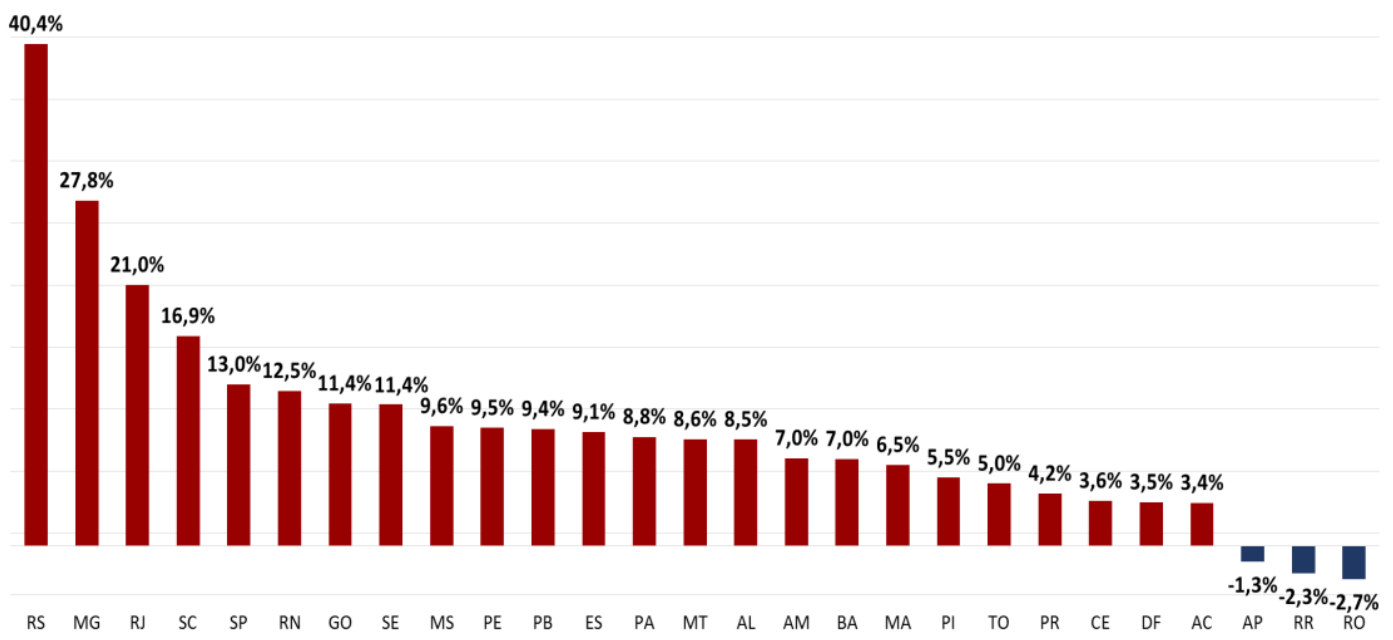

Gráfico 6. Necessidade de Financiamento Previdenciário \% RCL Estado do Rio de Janeiro. Fonte: FIRJAN

Em uma conjuntura de queda das receitas, a combinação de baixa capacidade de endividamento com elevada rigidez orçamentária fez com que a postergação de despesas via restos a pagar se materializasse como a principal fonte de financiamento dos estados. Souza (2010) chama a atenção para esta prática:

\begin{abstract}
De acordo com a Contabilidade Pública, os Restos a Pagar, na sua origem, destinavam-se a ajustar o encerramento do exercício financeiro com a continuidade da Administração Pública, visto que nem todos os pagamentos de despesas coincidem com o final do exercício e é normal que algumas despesas que dizem respeito a um exercício, fiquem para serem pagas no exercício seguinte. No entanto, as deficiências no planejamento orçamentário fizeram com que esse instrumento, fosse mal utilizado, passando a servir como instrumento de rolagem de dívida.
\end{abstract}

Não por acaso, os três estados que apresentaram as maiores dívidas e os mais elevados gastos de pessoal encerraram 2016 com mais restos a pagar processados do que recursos em caixa ${ }^{5}$, ou seja, fecharam o ano no vermelho. Como mostra o Gráfico 7, no Rio Grande do Sul a diferença entre o volume de restos a pagar processados e os recursos em caixa deixados em 2016 representou $42 \%$ da RCL, foram $\mathrm{R} \$ 14,5$ bilhões em despesas postergadas para 2017 , sem a devida cobertura. No Rio de Janeiro, $\mathrm{R} \$ 11,1$ bilhões, o equivalente a $24 \%$ da RCL, enquanto em Minas Gerais, $\mathrm{R} \$ 3,7$ bilhões, 7\% da RCL. Os outros dois nessa situação em 2016 foram Sergipe e Distrito Federal.

\footnotetext{
${ }^{5}$ A LRF veda a contração de obrigação de despesa que não possa ser cumprida integralmente no último ano de mandato, ou que tenha parcelas a serem pagas no exercício seguinte sem que haja suficiente disponibilidade de caixa para este efeito. 0 artigo 42 foi elaborado com intuito de evitar que, em último ano de mandato, sejam irresponsavelmente contraídas novas despesas que não possam ser pagas no mesmo exercício. Posteriormente, a Lei de Crimes Fiscais (2000) caracterizou como crime, punindo com reclusão de um a quatro anos, ordenar ou autorizar a assunção de obrigação em desacordo com a determinação do artigo 42. Dados não disponíveis para o estado do Rio Grande do Norte.
} 


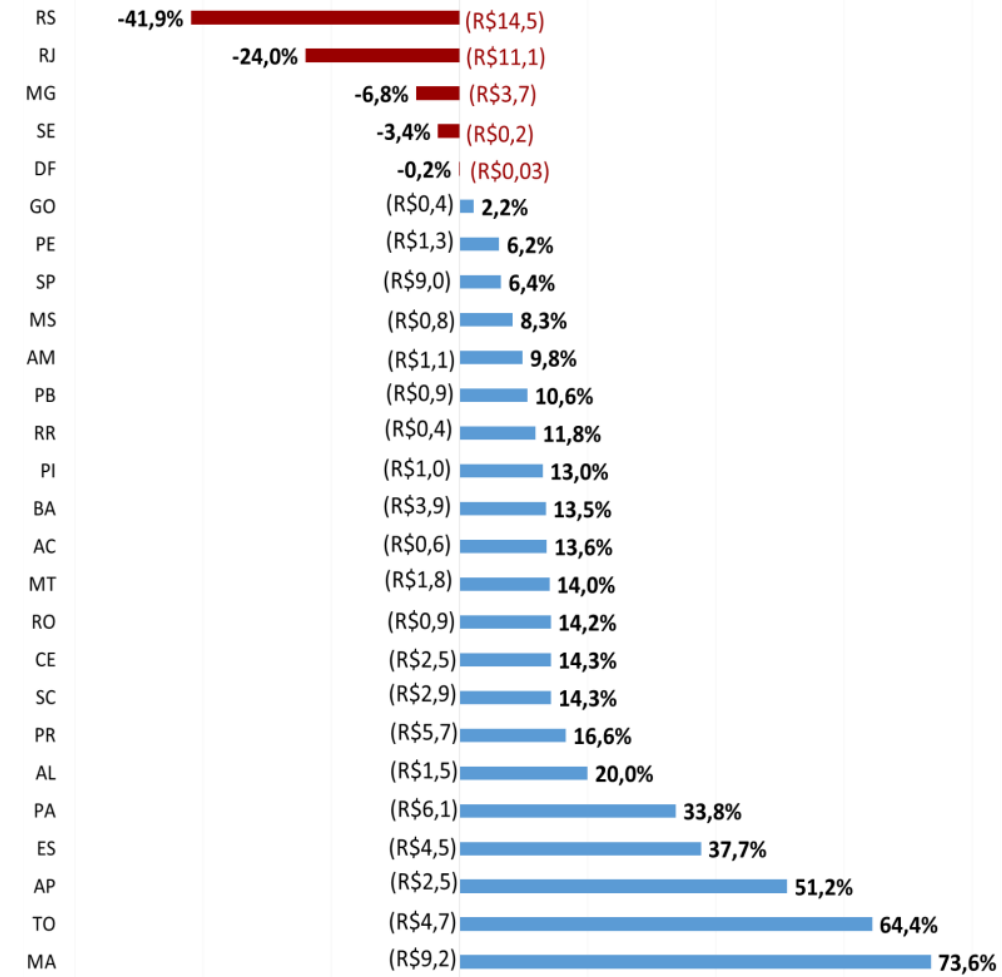

Gráfico 7. Disponibilidade de Caixa (R\$ Bilhões) \% RCL 2016.

Fonte: Secretaria do Tesouro Nacional. Elaboração Própria.

Nessa matemática perversa, tem sobrado pouco espaço para os investimentos públicos estaduais, como por exemplo obras de infraestrutura e equipamentos destinados à segurança pública. Frente a 2014, ano em que teve início a trajetória cadente da atividade econômica, os estados reduziram os investimentos em $\mathrm{R} \$ 34,8$ bilhões, uma queda de 53,4\% em termos reais, enquanto a redução da Receita Corrente Líquida foi de 5,6\%. Desta forma, em 2016, o investimento médio dos estados atingiu o patamar mais baixo dos últimos nove anos, ao alcançar 5,3\% da RCL - Gráfico 8.

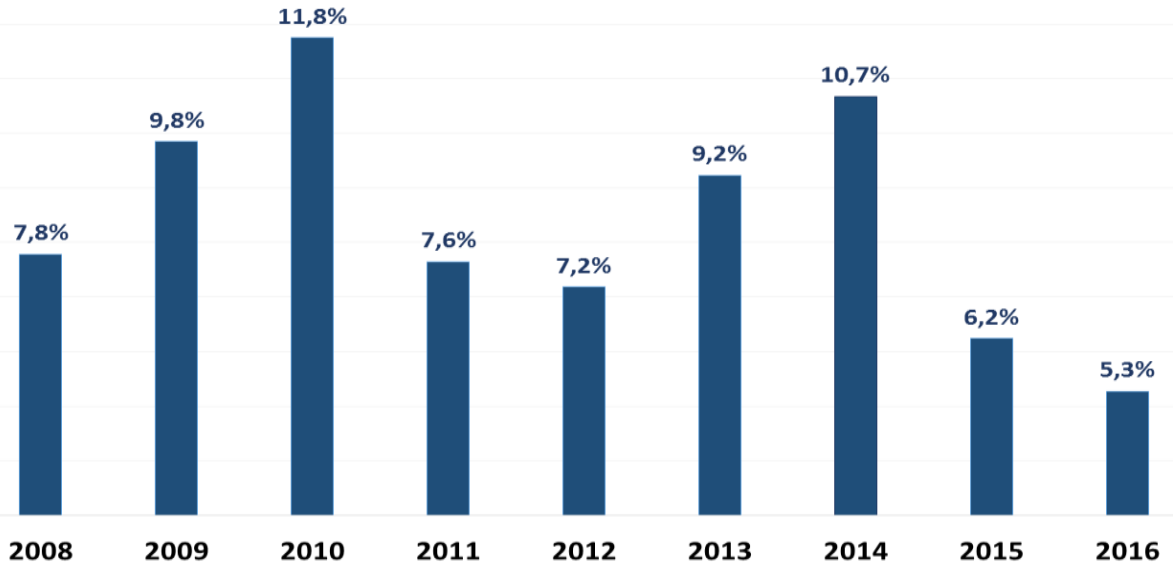


Gráfico 8. Investimentos \% RCL (Agregado dos estados).

Fonte: Secretaria do Tesouro Nacional. Elaboração Própria.

Em um momento de forte retração da atividade, o baixo nível de Investimentos é um desafio para a recuperação da economia e consequentemente da própria arrecadação de tributos. Como mostra o Gráfico 9, apenas três estados investiram mais de 10\% da RCL em 2016: Ceará, Piauí e Bahia. O Rio Grande do Sul é o estado que menos investiu no ano passado, apenas 1,8\% da sua RCL - desde 2014 este percentual não ultrapassa $2 \%$. Minas Gerais também integra o grupo de estados que investiu menos de $3 \%$ da RCL em 2016.

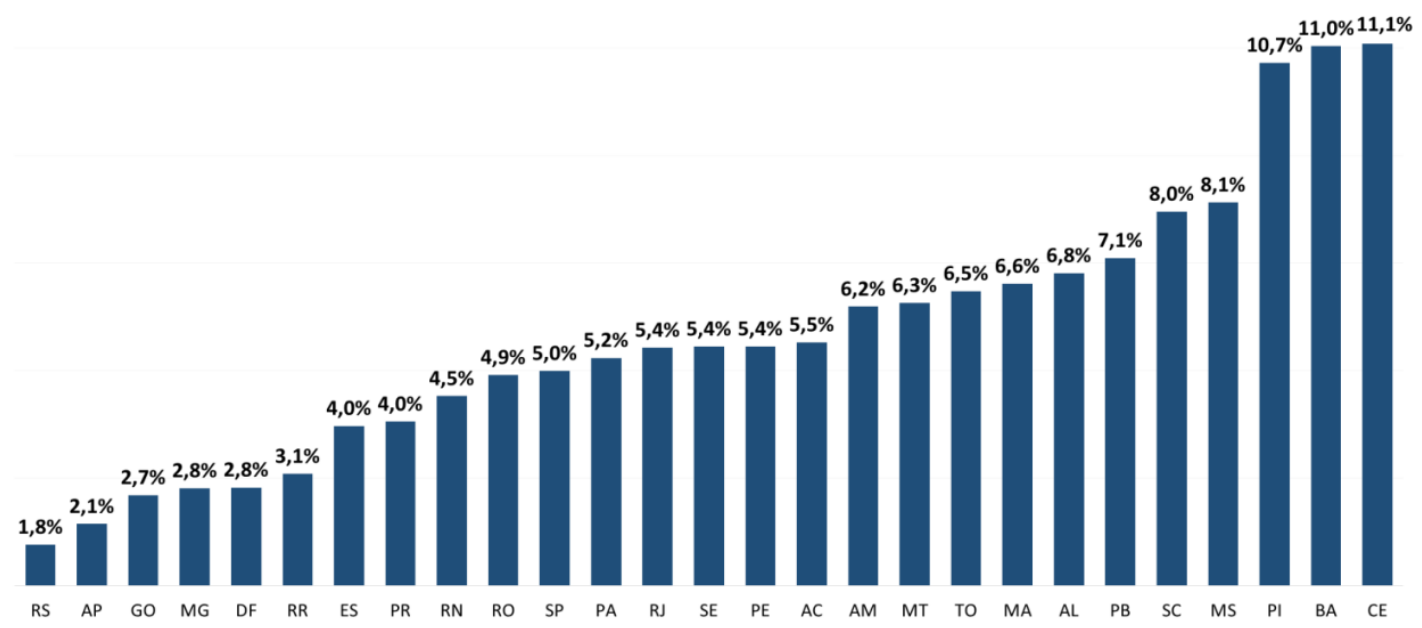

Gráfico 9. Investimentos (\% da RCL) - 2016.

Fonte: Secretaria do Tesouro Nacional. Elaboração Própria.

No caso do Rio de Janeiro, há dois anos destinara 16,5\% da RCL para Investimentos e em 2016 esse percentual caiu para 5,4\%, o menor nível desde 2008. Em termos absolutos significa uma queda de $\mathrm{R} \$$ 6,5 bilhões em investimentos do governo do estado - sozinho, o estado contribuiu com quase $20 \%$ da queda total de investimentos nos 27 estados. Como mostra o gráfico 10, o percentual da Receita destinada a Investimentos está no mesmo nível de 2008. Vale destacar que a Copa e Olimpíadas foram importantes para manter o nível de investimentos alto no Estado, contudo, com o agravamento da crise econômica o ajuste se fez inevitável a partir de 2015 . 


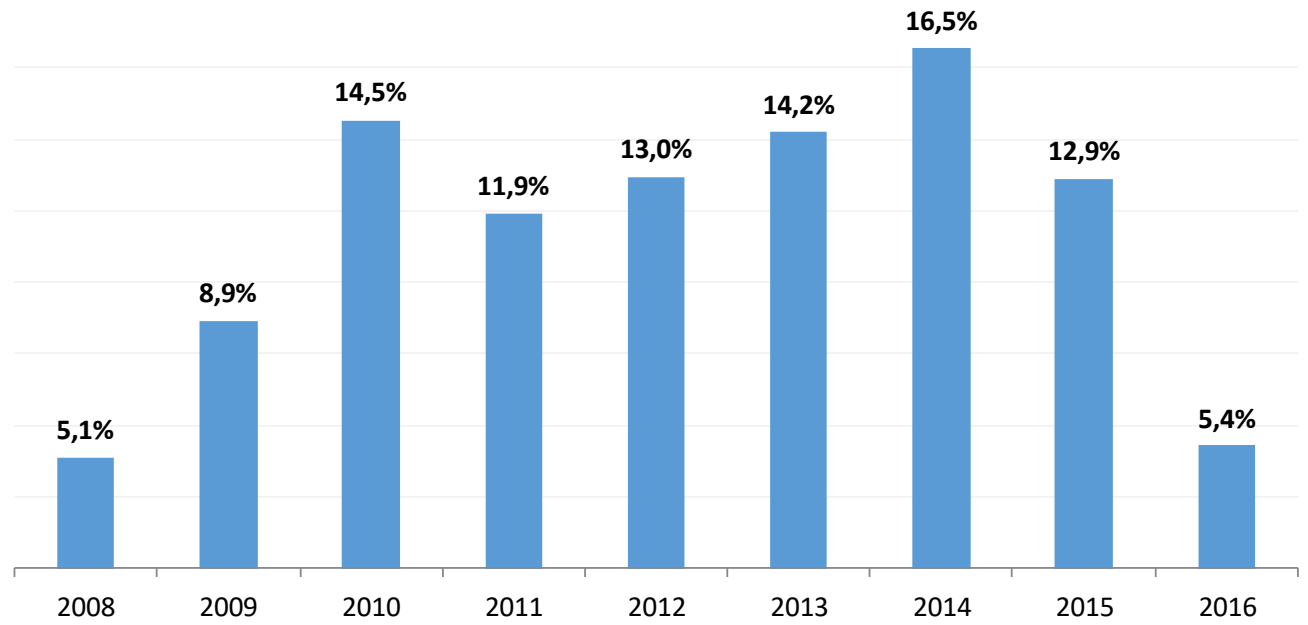

Gráfico 10. Investimento \% RCL Estado Rio de Janeiro.

Fonte: Secretaria do Tesouro Nacional. Elaboração Própria.

\section{CONCLUSÃO}

Este artigo analisou a situação fiscal das 27 unidades da federação brasileira, com foco no Rio de Janeiro. Com efeito, os estados em pior situação fiscal são Minas Gerais, Rio de Janeiro e Rio Grande do Sul. No que diz respeito à dívida, esses três estados são os únicos acima do limite de $200 \%$ da RCL definido pela LRF. O Rio de Janeiro é o estado com a dívida mais alta do país. Como resultado de sucessivos déficits orçamentários, nos últimos quatro anos a dívida fluminense reverteu praticamente toda a redução observada nos nove anos anteriores.

Em que pese a conjuntura econômica recessiva e seu consequente efeito negativo sobre a arrecadação tributária, o exame dos indicadores fiscais não deixa dúvidas do caráter estrutural da crise fiscal dos estados. O elevado comprometimento do orçamento com gastos de pessoal é uma realidade para a grande maioria, especialmente por conta do grande desequilíbrio previdenciário. Em apenas três estados a previdência não fechou o ano de 2016 no vermelho. Nos estados de Minas Gerais, do Rio de Janeiro e do Rio Grande do Sul as despesas de pessoal já superam 70\% da RCL, percentual muito superior ao teto de $60 \%$ definido pela LRF. 
A combinação de baixa capacidade de endividamento com elevada rigidez orçamentária fez com que a postergação de despesas via restos a pagar se materializasse como a principal fonte de financiamento dos estados. Não por acaso, os três estados com as maiores dívidas e os mais elevados gastos de pessoal encerraram 2016 com mais restos a pagar processados do que recursos em caixa. Postergaram mais de $\mathrm{R} \$ 29$ bilhões de reais para 2017 , sem a devida cobertura de caixa.

Nessa matemática perversa, tem sobrado pouco espaço para os investimentos. Frente a 2014, os investimentos dos estados caíram pela metade, atingindo o menor nível dos últimos nove anos. O Rio Grande do Sul foi o estado que menos investiu em 2016, apenas 1,8\% da sua RCL; Minas Gerais menos de 3\%. No Rio de Janeiro os investimentos caíram a um terço do nível de 2014 - sozinho, o estado contribuiu com quase $20 \%$ da queda total dos investimentos dos 27 estados no período.

Em vista desse diagnóstico, a adesão ao Regime de Recuperação Fiscal - RRF proposto pelo governo federal parece inevitável aos estados do Rio de Janeiro, do Rio Grande do Sul e de Minas Gerais. As contrapartidas exigidas pelo acordo atacam muitas das questões apontadas nesse estudo, mas não são suficientes. A sustentabilidade fiscal dos estados depende da reforma da previdência, de um amplo programa de privatizações e concessões, bem como de novas regras fiscais que visem o equilíbrio orçamentário intertemporal. Caso contrário, em poucos anos o Brasil estará discutindo mais uma renegociação das dívidas subnacionais.

\section{REFERÊNCIAS}

AFONSO, José; JUNQUEIRA, Gabriel. Investimento Público no Brasil é Mais Municipal que Federal. Revista de administração municipal - IBAM, Rio de Janeiro, ISSN 0034-7604, Ano 55, n.272, pp.18-25, Out-Dez/2009

CAETANO, Marcelo. Solvência fiscal de longo prazo dos regimes próprios de previdência dos estados e municípios. Texto para discussão. Instituto de Pesquisa Econômica Aplicada.- Ipea, Brasília, n. 2195, mai/2016.

FERREIRA, Pedro Cavalcanti. Investimento em infra-estrutura no Brasil: fatos estilizados e relações de longo prazo. Revista Pesquisa e Planejamento Econômico, v. 26, n. 2, agosto 1996.

FIRJAN. A situação fiscal dos estados brasileiros. Publicação de Conjuntura Econômica, Rio de Janeiro, abr/ 2017.

REZENDE, Fernando Antônio. Finanças Públicas. 2a. Ed. São Paulo: Atlas, 2001

SOUZA, Ana Cecília. Restos a Pagar: a última fronteira da transparência. Revista do Tribunal de contas do estado do Rio de Janeiro, 2010. 